\title{
The Rise Of BIM in Malaysia And Its Impact Towards Quantity Surveying Practices
}

\author{
Nurshuhada Zainon ${ }^{1 a}$, Faizul Azli Mohd-Rahim² and Hafez Salleh ${ }^{1}$ \\ ${ }^{1}$ Senior Lecturer, Department of Quantity Surveying, Faculty of Built Environment, University of Malaya, 50603 Kuala Lumpur. \\ ${ }^{2}$ Associate Professor, Department of Quantity Surveying, Faculty of Built Environment, University of Malaya, 50603 Kuala Lumpur.
}

\begin{abstract}
Building Information Modeling (BIM) is a new buzzword that is gaining a momentum within the construction industry in Malaysia, and worldwide. BIM is a way of working that involves the automation of the entire project team using a 4D model that can do many of the traditional fuctions of a Quatity Surveyor (QS). As BIM is removing more of the traditional work of QS, there are rising fears that it could threaten the viability of the QS professions especially for small firms that still rely on producing bills of quantities. This paper aims to review the challenges and opportunities gained from BIM advancement in QS profession, especially in Malaysia. Despite of serious cost and commercial challenges of BIM implementation, BIM will work wonder as a tool that will cut the amount of time QS have to spend on analysis and provides opportunities to direct QS talents towards being more efficient. This is resulting to better project coordination with a lot less conflict, a more sustainable building in the final instance and also throughout the process, as less time is spent on each stage.
\end{abstract}

\section{Introduction}

The construction sector shares $12.2 \%$ of world Gross Domestic Product (GDP), with the Global Construction 2025 reported that $70 \%$ more construction work will be going on around the world (Branson, 2013). In Malaysia, the construction sector grew by 8 to $10 \%$ with 3 to $5 \%$ shares of local GDP (Bank Negara Malaysia, 2015), indicate its significant role towards the global growth and locally. Thus, it is necessary for the construction industry to undergo evolution in the era of globalization with the aim of getting international competitiveness. Owing to its complex in nature and involvement of multidisciplinary parties, construction industry faces common cost, time, and quality issues. Nevertheless, the rise of Building Information Modeling (BIM) technology has emerged as of the application tools to meet the objective of escalating productivities in a construction project.

BIM gained its popularity due to its efficiency benefits in terms of time and cost saving, and increases coordination in information exchange. It is a new approach being adopted in managing construction project life cycle activities, from project design, construction, to facilities management (Eastman et al., 2011). BIM is defined as a digital representation of the physical and functional characteristics of a facility through share knowledge resource for information, forming a reliable basis for decisions during its life-cycle (Smith, 2014). Started with the use of BIM for architectural design, the conceptual underpinnings of the BIM technology go back to the earliest days of computing, as early as 1962
(Rodrigues, 2015). Today, BIM has become ubiquitous in the design and construction fields. In developed regions, the percentage of companies using BIM jumped from $28 \%$ in 2007 , to $49 \%$ in 2009 , and for $71 \%$ in 2012 (McGraw-Hill Construction, 2012). However in Malaysia, the architectural firms' BIM adoption rate was $20 \%$ (Mohd-Nor \& Grant, 2014), and only $10 \%$ of quantity surveying firms involved in BIM adoption since BIM was introduced 10 years ago (Ali, Al-Jamalullail, \& Boon, 2013) Additionally, engineering firms were found being steadily slow implement BIM (Rogers, Chong, \& Preece, 2015). As architectural, engineering, and surveying practices are the main players in BIM working environment, this can be a significant indicator of slow uptake of BIM in Malaysian construction industry as a whole.

In any project, cost and program are key performance indicators, in addition to quality. With the advent of parametric modeling, quantity surveyors (QS) play a significant role in contributing these two fundamental parameters to the modeling process from the outset and add the most value from the earliest stage. With BIM, the QS can provide detailed and accurate estimates, automate measurement, speed up traditional estimating process, and better capture, manage, and deliver project information. Despite its incredible benefit, BIM uptake among QS is still slow in Malaysia. There are also fear and resistance in the surveying practice towards the changes brought by BIM. There is resistance among QS to accept the changes as they suppose that BIM can perform most of the traditional QS

\footnotetext{
a Corresponding author: zshuhada@um.edu.my
} 
job scope which eventually will replace the QS (Matthews, 2011, RICS, 2011, NBS, 2012) which creates a situation that QS is no longer needed in the construction market. Thus, this situation derives an aim of this study which is to provide perspective on future of BIM in quantity surveying practices through reviewing the concerns of Malaysian QS and opportunities that are awaited.

\section{Brief History of BIM in Malaysia}

The adoption of BIM in Malaysia was driven primarily by the private sector since early 2000 . However BIM has only become a buzzword when the Jabatan Kerja Raya (Public Works Department, PWD) introduced BIM in construction project planning for public works in 2007 through their BIM Standard Manual and Guideline (Latiffi, et.al, 2013). In an effort to foster BIM environment in Malaysian construction industry, the Construction Industry Development Board (CIDB) has formed the BIM Steering Committee, BIM Roadmap, and BIM Portal, involving policy makers, practitioners, and academicians (CDIB, 2016). In order to help and promote the potential and benefits of BIM, PWD, CIDB and Multimedia Super Corridor Malaysia also offer initiatives namely roadshows, seminars, workshops, on top of affordable training program (Latiffi, et.al, 2014).

The Construction Research Institute of Malaysia (CREAM, 2012) reported on the earliest BIM projects in Malaysia. The National Cancer Institute of Malaysia in Sepang was the first project involved the application of BIM in Malaysia, followed by other projects under BIM Pilot program such as the Healthcare Centre Type 5 Pahang, and Administration Complex of Suruhanjaya Pencegah Rasuah Shah Alam. In these pilot projects, BIM was utilized for site modeling, visualization, design review, clash analysis, 4D schedule and simulation, and record modeling (Latiffi., et.a;, 2014). Recently, BIM in Malaysia is more likely to be used for complex and highrisk projects (PWD, 2011).

\section{Concept and the use of BIM}

BIM is defined as a modelling technology and associated set of processes to produce, communicate, and analyze digital information for construction purposes (Abdullah, et.al, 2014). Fundamentally, BIM is not simply a type of software but an integrated approach between human activity to produce digital representation of physical and functional characteristics of a building through relevant software.

BIM applications span over the entire life cycle of a facility. BIM is applied in project planning, design, pre-construction, construction and post-construction (operations and maintenance) stages. In planning stage, the project team can utilize BIM in analyzing space and understanding the complexity of land regulations and space standards, hence saving time and providing the team more time to create more value-added activities (Azhar, Khalfan, \& Maqsood, 2012). In this phase, advanced 3D laser scanning equipment is used to scan the site to determine the position of existing utilities accurately and then integrate them in the BIM model. On top of intensive use of BIM in designing, the user can perform quantity survey and get detailed estimates accurately which can be measured directly from the 3D models. The user can plan for site logistics and identify potential hazards on site, thus helping in the preparation safety plan. Project managers can benefit from scheduling and monitoring function with the help of 4D and $5 \mathrm{D}$ models. In post-construction stage, BIM is used for transferring the data of building (spaces, systems and components) into facility management operations, keeping track of building assets, and enable scheduled maintenance and provides information of building maintenance history

All the information of functional and physical characteristic of a building and the life cycle of project are included in BIM in a series of smart object, providing better decision support in the process of project development (Azhar et al., 2008). Besides, BIM allow fast and accurate updating of changes, while in conventional 3D CAD, the plans, sections and elevations are used to describe the building as independent 3D views. Furthermore, the man-hours needed to establish reliable space programs in BIM will be reduce as compared to the conventional technology. BIM also enhances effective communication between the parties involved in the project development. For example, the information such as the details of procurement, drawings, submittal processes and other specifications can be linked together in BIM, whereas the conventional approach is paper-based modes of communication. BIM increases the confidence in the completeness of the scope. This can be done through a clash analysis to detect conflict, collision, and interference due to the model form in scale, $3 \mathrm{D}$ space, so the user can visually check the interference in all the systems.

\section{BIM in Quantity Surveying Practice}

Quantity surveying is vital in construction field to control and manage the cost throughout the project life cycle. Traditionally, taking off and bill of quantities demanded long working hours and effort to be produced, with highrisk of human errors. As the building works are becoming more and more complex, BIM has developed into the mainstream in construction industry in developed country, BIM is expected to be embraced in QS firms to boost up the effectiveness in term of cost and value of construction processes (BCIS, 2011). Quantity surveying requires immense knowledge and skillful interpretation and practical use of the knowledge (Vineeth \& Jenifer, 2014). Implementation of BIM brings opportunity to quantity surveying field in the cost management functions.

Bill of Quantities (BQ) is an important tool to carry out cost management in contruction projects. BIM technology provides a fifth dimension (5D) of BIM which can automatically produce BQ. The collaboration and integration feature of BIM in the automatic 
production of $\mathrm{BQ}$ is an enhancement to the BIM technology. This is effective in eliminating the lengthy and tedious ways of tranditional taking off as well as reducing human error. BIM is able to extract exact quantities and areas that are used to estimaste cost at anytime during the project design stage. Not only that, QS is able to recognize and relate how the total project cost is made up by each elements or spaces of the building through BIM as BIM eases the identification of relationship of quantities versus the locations and costs. This enhances the competency of QS through the comprehensive knowledge of cost determinants which in turn generate cost estimation with high accuracy and reliability. Any changes in the design will actually being automatically updated through the quantities drawn out from the modified model; it does not require QS to redo the taking off as in traditional method. The cost estimating integration with the BIM design engine, it allows the project team to execute value management durong the design phase efficiently.

BIM is capable of providing a more intensive and detailed drawing compared to the traditional 2D drawing where misunderstandng and wrong assumption may be made. The more comprehensive construction information and more pricise BQ can diminish the gap among the project team members. Through understanding on how to extract the quantity from building model, bidders are able to bid with intensely competitive price.

Through the 5D feature of integrating cost estimation with building model, the estimating job of a QS has is becoming simple and straightforward as compared to the conventional paper drawing. With BIM, construction field is heading to a paperless construction.

\section{Methodology}

This study was conducted during September - December 2015 to retrieve articles related to BIM and QS issues literature. No specific key words required as inclusion criteria; a relatively small number of studies exist on the topic. Articles were retrieved from diverse platform which include journals, technical reports, and news. The reference lists of each article were reviewed in detail to find additional articles. A group of reviewers $(n=46)$ independently read articles in full text, and recorded the main findings of challenges and opportunities of BIM in quantity surveying in Malaysia, consequently confirmed by a number of Malaysian certified QS $(n=3)$.

\section{Findings}

\subsection{Challenges of BIM for Quantity Surveying Practice}

Clearly with the rate of BIM adoption among QS firms, there are challenges spelled out, as follows, in adopting BIM as it is relatively new to surveying practice:

\subsubsection{Teamwork and collaboration}

As new ways for cooperation between the project team has been offered through BIM implementation, some problems may arise among them. For instance, an issue may occur when the method for sharing model information among the team member is being determined. If traditional drawings on paper have been used by the architect, then a third party will have to construct a model to be used for the estimating and planning of the construction project.

In addition, if the team members use a wide variety of tools for modelling, then the project may require some other tools to move the models between different environments or to combine them together. Hence, it may add complications or cause errors to the project. In order to overcome this issue, the Industry Foundation Classes (IFC) standard can be adapted when data is being exchanged throughout the project life cycle. Other than that, team members can also use a model server that can enable exchange of information between the BIM applications through adaptation of IFC standards.

\subsubsection{Legal issue}

Challenges in BIM implementation may arise when the question of ownership and responsibility of the various design, analysis and datasets are asked among the team members. It will be a challenge to determine who is to pay for it and who will be in charge of its precision and accuracy. These challenges are being questioned by the experts when BIM is used in their projects. A building model will be needed by the building owners to enhance the maintenance, renovations and operations once they educate themselves about the benefits of BIM.

\subsubsection{Use of information and changes in practice}

Firms that can coordinate the design phases and include in-depth knowledge about construction will get the highest advantage as BIM implementation in a project stimulates the assimilation of construction related information and knowledge in the beginning of the design phase. Furthermore, the arrangements in contracting that prioritizes excellent cooperation will benefit the owners more when BIM is applied in a project. In addition, when BIM is applied in a certain project, a building model will be constructed and shared among the project team as it is the basis of every work process in the project. Knowledge and time are two key components to facilitate this change that will be faced by the companies, as they are also required for every important transformation in technology.

\subsubsection{Implementation issue}

To effectively start using BIM, firms need to upgrade their hardware, obtain the necessary software, and also require their employees to go for the correct BIM training in order to transform a $3 \mathrm{D}$ environment into a complete 
BIM system. The firm has to comprehend every detail and plan for the implementation carefully before any transformation can take place. In addition, the firm can appoint managers to head a team responsible for planning the BIM implementation by prioritizing budget, cost and time as their guidance. Other than that, an adoption plan could be developed to predict how the future implementation changes will impact the firm's partners and clients and also how it will affect its internal departments.

\subsubsection{Financial and time considerations}

In order to implement BIM successfully, a firm needs to periodically upgrade their hardware in order to run the processing software. It is obvious that the requirement of a big technology component to implement BIM has become a challenge for the surveying industry in Malaysia. However, by preparing the same software from similar vendors for all the companies, the issue of some hardware and software being hard to operate could no longer be a bother for the industry players. Hence, in order to fix any technical issues regarding BIM adoption, there will be some impact on the firm financially as well.

According to Autodesk (2013), the price for Building Design Suite Premium, an entry level software for BIM, is US\$6,825. With the current exchange rate being US\$1.0:RM4.21, that makes the price in Malaysia to be RM28,749.00. Furthermore, the cost calculated beforehand only includes the purchase of the most basic BIM software. The firm has to consider costs to train their employees and even hire new workers who are equipped with the knowledge and skills in BIM as they move forward to internalize a new working environment in their firm. It can be deducted that adopting BIM requires the firm to make a huge investment financially as only large organizations can afford the costly technology.

In order to transform a company to being accepting of a new technology such as BIM, a lot of time will be consumed and this is seen as a challenge as construction projects are highly affected by time. In Malaysia's construction industry, BIM experts are still very low in number. Hence, firms need to allocate time and also money in order to find the best experts to assist them in BIM implementation. In addition, firms that decide to send their workers for training in BIM technology would also have to consider the additional time and cost needed for them to master and learn the processes entirely.

\subsubsection{Process change}

For an organisation to adopt BIM fully, there will be essential and basic changes to its operational processes. Once a company successfully adopts BIM, the process of design will be brought forward to the start of the project. In addition, it will also be completed sooner with a completion level higher than those of traditional processes. Furthermore, BIM experts have considered
Autodesk, Bentley and Nemetschek to be among the technology platforms that are interoperable even though they do not run that smoothly together, despite there being some protests to it.

\subsubsection{Human resource and organisational issue}

For any organisation to fully adopt BIM in their projects, their human resource department will need to go through a complementary change in terms of their skills alongside an essential process change within the organisation. Furthermore, there will also be simultaneous increase of competency in the supply chain of the project, which also includes the contractors, designers, and also the developers.

People working in the organization can also be another challenge to face. When the important people in the firm are reluctant to accept the new tools and technology, it makes it that much harder to change their behaviour into liking and accepting them. When the staff resists and show reluctance to BIM, it will become a big challenge to the top management to persuade them to accept the new change to the organization. Their reluctance to learn something new or try the new softwares and technology will be the hardest challenge that the top management will have to overcome in order for BIM to be implemented successfully.

The role of top management is the most crucial as they have to decide the direction and the plans of action for the organisation to adopt the new technology while reducing the employee's resistance to change. In addition, the employees will be motivated as they witness the organisation's dedication in fulfilling their responsibilities seriously. The motivation shown to the employees is one of the ways to help decrease the reluctance of the employees in accepting the new change as well as to encourage them to be more confident in trying out the IT applications themselves.

In addition, there are some organisations that are scared to take the risk in changing their business process by adopting BIM. They worry about the huge uncertainty that may or may not affect their established firms, as well as the large cost that they have to bear. Other than that, managing the big change in terms of technology may also cause a challenge for the managers. The staff may feel threatened or anxious by the new technology that is involved with accepting BIM as they feel that their roles and jobs in the organisation will be completely taken over by the softwares and hardwares that BIM requires in order to function. Hence, managers must know how to tackle the technology change in the organisation.

Furthermore, another challenge faced by the organisation is their belief that their well-recognized firms will be affected by the new technology that comes with BIM implementation. When a new technology is being adopted, the business processes of a firm will also be affected, which can also impact the firm's significant rate of output. This, in turn, will also increase the risk in producing the outcomes of a project as well as the client's preset goals. 


\subsubsection{Professional support}

In Malaysia, the Government constraints and mandates the limits of the Engineering Consulting Services (ECS). Even though BIM has been known to provide interchange of electronic data with no boundaries, the management of professions, trades and industries are still kept fixed in cultural and geographical boundaries, as well as political identities. As a step to break down these barriers in the ASEAN community, there have been some movements in the region.

However, aside from the complex projects, most of the local companies are still being operated by local staffs that are following the local guidelines and mandates. Hence, some potential barriers have been found in various countries as well as in Malaysia, in order for BIM to be adopted in Malaysia's ECS. Therefore, it has been proven that in order for BIM implementation to be successful, there must be presence of consultants or professionals equipped with the skills and expertise to support it.

\subsubsection{Technical challenges}

There are obvious reasons as to why BIM adoption in Malaysia has not really been as much as anticipated. It is hard to adopt new information technology (IT) in the industry due to technical reasons as compared to social issues. Problems such as the lack of support system, difficulty to understand the complex softwares and also the low number of skilled technical experts are among the reasons.

Furthermore, BIM may have been accepted at a low rate because of the need for detailed and precise models to fix the issue of interoperability. Other than that, in order for important information to be communicated and integrated successfully among the components, there is a requirement for excellent practical strategies to be developed. This could lead to another technical reason as to why BIM has not been the choice for some firms. In addition, they also have to ensure every data developed is computable as it is part of BIM's technical requirements.

\subsubsection{Management}

Currently, there have not been any specific directions or orders in ways to use or implement BIM. There are no clear instructions on how to use and apply BIM in construction practises. Even though a few software companies have developed some products to help with the implementation of BIM, they have only managed to cover the aspects of quantity instead of implementing it as a whole. Therefore, for BIM to be adopted by firms easily there must be some clear and specific guidelines to be followed and the steps to implement BIM must be standardized for all firms. Another management challenge is the question that arose among the stakeholders, which is who shall be responsible for developing the models and how the costs will be distributed. Hence, to clear these issues, solutions have to be created by researchers, vendors and professional organizations together so that the use of BIM will increase in the Malaysian industry.

Before BIM, the facilities manager had very limited influence in the planning process of the building. They were only able to introduce strategies to maintain the building after the owner has received possession of the building. With implementation of BIM, the managers can be included in the stages of designing and construction. With BIM's visual ability, stakeholders such as tenants, maintenance staff and also service agents, can get a hold of any information that they might need even before the completion date. The biggest challenge will be for the owners, as they have to plan wisely for the right time to allow all the different parties to be included in the early processes of the building.

\subsection{Opportunities for Quantity Surveyors}

The competitiveness of QS is highly improved. As the cost estimation can be done through the quantities extraction at any stages during the design (Boon, 2009), the efficacy of a QS is highly enhanced. For example, with conventional way, QS is only able to finish up a complicated earthwork in couple of days but by extracting the quantities from BIM only takes less than an hour. When variations arise, QS can re-extract the quantities from the modified model and avoid the tedious human measurement. A competent and high efficiency QS poses better chances in surveying field. Not only that, the improved quality of estimation produces quality tender which will enable the QS to help company to open up more business opportunity and manage to get repeat business by winning the tender (Autodesk, 2003).

\subsubsection{Transformation in job scope}

Through the benefits brought by BIM to the surveying field in term of ease of quantity take off (Davidson, 2008), QS in malaysia do not need to spend time to measurement and find out the dimensions in from a $2 \mathrm{D}$ drawing. Unnessary assumptions and human errors can also be avoided. Now, with a highly accurate BQ produced in a very short time, QS is freed up to do more on cost management not in term of the manual taking off and adding up. There is no doubt that the QS still need basic skills regarding measurement to make use of the BIM technology, however, QS now saves more time and they are now no longer a wetware calculator, but they need to think more on what client's needs and wants. There are so many aspects that a QS need to cover.

QS not only provide advices on the construction methods and construction materials, QS also need to handle the legal issues. QS also have to be major on feasibility studies, value management, cost planning, tendering and dispute resolution (Gee, 2011). This opens the gate for Malaysian QS to involve in a construction project more comprehensively, but not major in 
measurement like current industry practice. This is heading to the QS job perspective in developed country construction industry, the best example to cite will be United Kingdom.

\subsubsection{Re-branding of Quantity}

With BIM, it is an era for Malaysia QS to move away from just $\mathrm{BQ}$, there is a rebreanding their job from a profession that only prepares $\mathrm{BQ}$ to a higher end consultants. In future, BIM will turn QSs to profession doing cost management, in term of cost modelling and also general advisor in pre-contract stages. QS is no longer branded with "Construction Industry Accountant", but also branded as construction industry legal specialist as they are the one to handle the legal based issues in quantity surveying field such as dispute resolution and giving legal advices regarding construction contract issues such as the procedure and situation where the contrcator is entitled from variation claim, the liability and risk allocation of each parties in the contracts and so on. QSs' proactive and knowledge based advices taking in all the aspects and situations of a project in consideration is important to the client (Verster, 2006).

Not only limited to that, by eliminating the lengthy quantity take off by BIM, QSs can be more engaged in contruction management especially value management and risk management. Other than that, QSs also involve in giving advices on safety and healthy and also quality control (Cunningham, 2014). Hence, BIM has provide the opportunity for QSs in Malaysia surveying to be rebrand from the root as a measuring profession to a profession serving towards value-added into a project. BIM aids the Malaysian surveyors to handle numbers, measurements and the rigid measurement rules with ease and helps them to think more on strategy by utilising critical thinking.

\subsubsection{Globalization}

BIM opens up the gate for QS in Malaysia to have a same communication platform. In conventional way of current Malaysia surveying practices, QS are using the Standard Method of Measurement of Building Works Second Edition (SMMS) as their measurement rules reference. Different standard menthos of measurement are used in different places. This BIM, there is a communciation barrier between the QS across different region. According to Heiskanen (2014), the very first international survey carried out in 2013 revelaed that consultants that do not adopt BIM were struggled to secure international project. Malaysian QS do not face difficulties when engaging in an internatioal projects where there are different surveyors from different backgorund who has previously learnt different standard methods of measurements. BIM softwares has ease their works without background barrier. This is one of the contribution factor to the success for local contractor to strive for success in international projects as the coordination and communication are greatly improved trough BIM (Broquetas, 2010).

\subsubsection{Beyond limit}

Malaysian surveying industry produces QS that are expertise in measurement with local standard rules og measurement. When they are to engage in international project or being posted to other branch of company overseas, they requires intensive training to learn the Qs practices in other country. Hence, the possibility of a QS to venture into international market is hard and limited due to the resistance to be accepted by international surveying market as different places poses different practices.

BIM is seen as a solution to this problem. It is easier for Malaysian surveyors to venture to international market as BIM is linked to software to enabe extraction of quantity. Whenthe surveyors know how to handle the software, it takes a very short time for a QS to catch up with the job scope especially in producing accurate BQ. The other aspects such as the legal aspect and also the risk and value management is a broad knowledge and no region boundary as it is something critical and analytical which requires QSs' to think out of the box.

Therefore, BIM is a tools that enables Malaysian surveyors to go beyond the limits, they are no longer bound to just one country. They can hop to different countries and still serve as QS with ease. BIM enables QSs not to be rooted and stucked in to serve in one country and cannot go far. To see from other perspective, surveyors and experts from other places can also be imported to gain their stregth and power so that they can be adopted in Malaysia surveying field. This is a vice versa relationship.

\section{Conclusion}

Through the continuous advancement in technology, construction industry cannot deny the changes but have to adopt it. BIM, as the latest trend in construction industry, can help to improve the construction process in so many ways such as providing rapid visualization, giving better decision support, providing rapid and accurate changes updating, providing better and efficient communication and so on. All these aspects meant to improve and secure the overall quality of the project, making local construction project to be more competent in international construction industry. BIM not just emphasize on the design stages, it is actually a comprehensive technology which covers throughout the pre-construction stage, construction and post-construction stage.

The challenges that come with BIM implementation affect every sector of the organisation that wish to adopt it. There are challenges in teaming and collaboration as well as the question of documentation ownership and production. Furthermore, implementation issues, use of information, changes in process as well as financial and time considerations are some other challenges that must be faced by the organisations. As people are one of the most tangible factors, the challenges will greatly affect the human resource and organisational 
issues of the firms. In addition, the challenges that may be faced by the organisation could also be categorized into management and technical challenges. It is clear to see that BIM carries along a lot of issues and challenges with its implementation. However, if an organisation can manage smartly and take all the right steps in overcoming them, it will get to experience the convenience and powerful technology that BIM can offer. Now leaps far and see a bigger picture on the opportunities for Malaysian surveying practices with BIM implementation. BIM aids in the quantity surveying practices in their works on preparing BQ, cost estimation, updating of cost and even in tendering process. With all this, BIM eventually is a way for the QS to get out from the conventional method of doing quantity take off which is very tedious which in turn will transform the job scope of surveyors, making them to be rebrand as higher end consultants. This is not the end of their opportunity as BIM provides a platform for local surveyors to integrate internationally with other surveyors. Hence, local surveyors are not nationally restricted. In fact, they can go beyond the limit and works in international established companies or projects with ease. This is also a golden opportunity for local surveying practices to immerse with new strength and knowledge from other places as BIM ease effective communication.

\section{Acknowledgement}

This research is supported by British Council NewtonUngku Omar Fund Institutional Links (ID: 172726659) and University of MalayaInstitute of Research Management \& Monitoring (IPPP) (grant no: IF0092015.

\section{References}

1. Abdullah, S.A, Sulaiman, N, Latiffi, A.A, \& Baldry, D. (2014). Building Information Modeling (BIM) from the Perspective of Facilities Management (FM) in Malaysia. Universiti Tun Hussein Onn Malaysia, retrieved from

http://eprints.uthm.edu.my/5425/1/IRERS_2014_2_ U.pdf.

2. Ali, K.N., Al-Jamalullail, S.N.N.S.I, \& Boon, T.C (2013), Building Information Modeling Awareness and Readiness among Quantity Surveyors and Quantity Surveying Firms, Universiti Teknologi Malaysia-Royal Institution of Surveyors Malaysia, Technical Paper.

3. Autodesk. (2013). Autodesk Building Design Suite. Retrieved from http://usa.autodesk.com/autodeskbuilding-design-suite/compare/.

4. Autodesk. (2003). Building information modelling in practice. Retrieved from http://www.ddscad.com/BIM_In_Practice.pdf

5. Azhar, S., Khalfan, M., \& Maqsood, T. (2012). Building information modelling (BIM): now and beyond. Australasian Journal of Construction Economics and Building, 12(4), 15-28.

6. Bank Negara Malaysia (2015), Economic and Financial Developments in Malaysia in the First Quarter of 2015, retrieved from http:/www.bnm.gov.my/files/publication/qb/2015/Q 1/1Q2015_fullbook_en.pdf.

7. BCIS. (2011). RICS 2011 Building Information Modelling Survey Report. Retrieved from http://www.bcis.co.uk/downloads/RICS_2011_BIM_ Survey_Report.pdf

8. Boon, J. (2009). Preparing for a BIM Revolution.13th Pacific Association of Quantity Surveyors Congress (PAQS 2009). (P.35).

9. Branson, A (2013), Global Construction 2025, Building.co.uk, retrieved from http://www.building.co.uk/global-construction2025/5057217.article.

10. Broquetas, M. (2010). Using BIM as a project management tool: how can BIM improve the delivery of complex construction projects?. Master degree dessertation, University of Applied Sciences, Stuttgart.

11. Bryde, D., Broquetas, M., \& Volm, J. M. (2013). The project benefits of building information modelling (BIM). International Journal of Project Management, 31(7), 971-980.

12. CIDB (2016). BIM Training, retrieved from http://www.bimcenter.com.my/.

13. CREAM (2012). A Case Study of BIM Implementation in Malaysia, retrieved from http://www.myconstructionresearch.com/index.php/p ublication/integrated-design-deliverysolution/file/12-bim-implementation-in-malaysia.

14. Davidson, A., R. (2008). A study of the deployment and impact of Building Information Modelling Software in the Construction Industry. Retrieved from http://www.engineering.leeds.ac.uk/e engineering/documents/AndrewDavidson.pdf

15. Eastman, C., Teicholz, P., Sacks, R., \& Liston, K. (2011), BIM handbook: A guide to building information modeling for owners, managers, designers, engineeris, and contractors, Wiley: New Jearsey.

16. Gee, C. (2011). The influence of buidling information modelling on the quantity surveying profession.

17. Latiffi, A.A., Brahim, J, Mohd, S, Fathi, M.S. (2014). The Malaysian Government's Initiative in Using Building Information Modeling (BIM) in Construction Projects, ASEA-SEC-2, Bangkok, November 3-7.

18. Latiffi, A.A, Mohd,S, Kasim, N, \& Fathi, M.S. (2013). Building Information Modeling (BIM) 
Application in Malaysian Construction Industry. International Journal of Construction Engineering and Management, 2(A), 1-6.

19. NBS. (2012). National BIM Report 2012. Retrieved from http://www.thenbs.com/pdfs/NBS-

NationalBIMReport12.pdf

20. Matthews, D. (2011). Rise of the Machines: BIM and $Q S$ 's. Retrieved from www.blackenewport.co.uk/bna-news-andmedia.asp? $\mathrm{id}=90$

21. McGraw-Hill Construction (2012), The business value of BIM in North America: Multi-year trend analysis and user ratings smart market report, retrieved from http://bimforum.org/wpcontent/uploads/2012/12/MHC-Business-Value-ofBIM-in-North-America-2007-2012-SMR.pdf.

22. Mohd-Nor, M.F.I \& Grant, M.P. (2014). Building Information Modeling (BIM) in the Malaysian Architecture Industry, WSEAS Transactions on Environment and Development, Vol.10, 264-273.

23. PWD (2011). Laporan Tahunan Jabatan Kerja Raya 2011, pp 28-29. Retrieved December 6, 2015, from http://www.jkr.gov.my/var/files/File/dokumen/lapora n_tahunan_jkr_2011.pdf.

24. Rodrigues, R. F. O. (2015). Otimização do processo de pré-dimensionamento de fundações diretas com recurso à metodologia BIM.

25. Rogers, J, Chong, H.Y, \& Preece, C. (2015). Adoption of Building Information (BIM) technology: Perspectives from Malaysian engineering consulting services firms. Engineering, Construction, and Architectural Management, 22(4), 424-445.

26. Smith, P. (2014), BIM implementation - global strategies. Procedia Engineering, 85, 482-492.

27. Verster, J. J. P. (2006, April). Managing cost, contracts, communication and claims: A Quantity Surveying perspective on future opportunities. In Proceedings of 1st ICEC \& IPMA Global Congress on Project Management, 5th World congress on Cost Engineering, Project Management and Quantity Surveying (pp. 23-26).

28. Vineeth, R., \& Jenifer, P. (2014). Role of Building Information Modelling ( Bim ) in Quantity Surveying Practice. International Journal of Civil Engineering and Technology, 5(12), 194-200. 